\title{
Antibacterial Activity of Boehmite Nanoparticles Synthesized by Arc Discharge in Deionized Water Technique
}

\author{
Halah H. Rashed \\ Applied Science Department, University of Technology, Baghdad-Iraq. \\ E-mail: hala_hassan8140@yahoo.com
}

\begin{abstract}
In this work, boehmite $\mathrm{AlO}(\mathrm{OH})$ nanoparticles were synthesized by arc discharge technique. The structural, surface morphology and optical properties were characterized by X-Ray Diffraction (XRD), Fourier transforms infrared spectroscopy (FTIR), Atomic Force Microscope (AFM) and Ultraviolet-Visible-Near In far Red spectrophotometer respectively. XRD results show pure orthorhombic crystalline structure of gamma-AlO $(\mathrm{OH})$. FTIR absorption spectrum shows that the boehmite nps have the octahedron region which extends from $\left(400-800 \mathrm{~cm}^{-1}\right)$ corresponding to the vibrational frequencies of $\mathrm{Al}-\mathrm{O}$ bonding. The AFM shows that boehmite NPs are spherical in shape and the average diameter is around $89 \mathrm{~nm}$. Finally the optical properties results show that the boehmite nps have absorption peak at $210 \mathrm{~nm}$ and an optical band gap of $4.1 \mathrm{eV}$.

Boehmite nps was examined susceptibility to effect on the different types of bacteria, Escherichia coli (Gram-negative) and Staphylococcus aurous (Gram-positive) strains bacteria.

Boehmite NPs showed excellent antibacterial activity against two types of bacteria. Also, Staphylococcus aurous exhibited the highest sensitivity to boehmite NPs while Escherichia coli were the least sensitive. [DOI: 10.22401/JNUS.20.1.08]
\end{abstract}

Keywords: Arc discharge in deionized water technique, Boehmite nanoparticles, Optical and structural properties, Antibacterial activity.

\section{Introduction}

Boehmite is an aluminum oxide hydroxide $\gamma-\mathrm{AlO}(\mathrm{OH})$ mineral [1]. It has been used to increase the rate of a chemical reaction without undergoing any permanent chemical change, polishing or cleaning hard surfaces by rubbing or grinding and as electrical insulating materials[2], it is also used as an absorbent, a catalyst, optical material, coatings, composite reinforcement material in ceramics, cosmetic products, a substance that enhances the body's immune response to an antigen, it's essential material for produce high impurity alumina by different methods such as sol-gel and precipitation [3].

Among these important applications, boehmite nanoparticles are used as antibacterial agent due to their ability to damage the cell wall of bacteria. This resulted into inhibition of bacterial cell growth [4].

There are several methods to synthesize boehmite NPs for example: thermal decomposition of gibbsite $\left(\gamma-\mathrm{Al}(\mathrm{OH})_{3}\right)$, hydrolysis of Al-alkoxides at different $\mathrm{pH}$, and precipitation of inorganic Al-salts in aqueous media [5].
Electrical arc discharge technique in liquid media is known as a relatively simple and cheap tool for synthesis of nanostructures of different materials [6], it offers several advantages because of lack of need for vacuum equipments, low pollution, less formation steps leading to a high-the amount of the material and cost-effective procedure to generate a high production of nanoparticles [7].

\section{Experimental work}

\section{I- Synthesis of Boehmite NPs}

Aluminum rods (Germany, 99.99\% purity) $1 \mathrm{~mm}$ in diameter and $10 \mathrm{~cm}$ length were used as the electrodes. They are placed in front of each other at a distance of $1 \mathrm{~mm}$ submerged in deionized water (DIW) $(\mathrm{pH}=6.5)$.

The experimental set up includes four main parts:

(i) Stabilized voltage power supply type (Farnell) regulates voltage through the electrodes in order to ionize the medium between the electrodes.

(ii) A dielectric medium (water) is used to create the boehmite nanoparticles 
suspension and to facilitate nanoparticles dispersion;

(iii) A Pyrex beaker containing the deionized water to collect the boehmite nanoparticles

(iv) A magnetic stirrer and stirring bar. These components are demonstrated in Fig.(1).

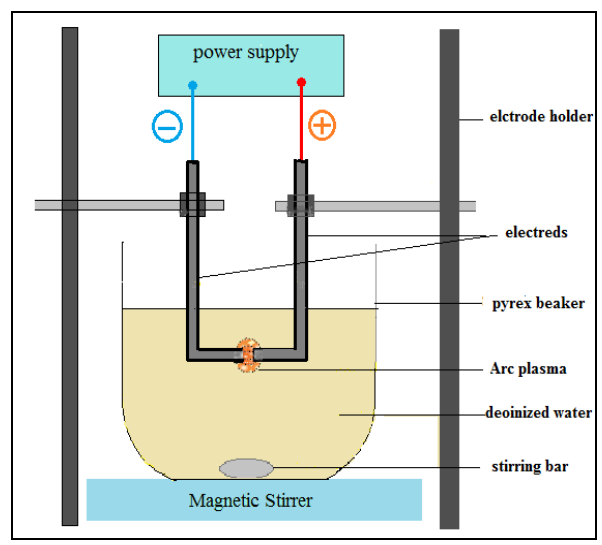

\section{Fig.(1): Experimental set up of arc discharge experiment.}

The two aluminum wires connected to the stabilized power supply supplied with 200 volt and the electric current of $20 \mathrm{~mA}$. Aluminum rods were immersed in $40 \mathrm{ml}$ DIW and placed in front of each other at a distance of $1 \mathrm{~mm}$. When the end of two electrodes approached, spark discharge generated. This spark discharge caused to the increase the electric current from 20 to $80 \mathrm{~mA}$ as a result the drop of resistance between them, very high temperature generated and able to vaporize of aluminum metal.

Aluminum particle were cooled quickly by DIW atoms, and then specifically scattered and reacted with the DIW atoms. The rapid cooling is working to form clusters could be the nucleus for further formation of particles of aluminum oxide hydroxide nanoparticles, because of the Al-O bonding associated with $\mathrm{OH}$ bonding of water. Therefore boehmite nanoparticles could be easily synthesized by this technique in one stage preparation.

The color of Boehmite colloidal was transparent and slowly converts to milky like after 10 min as shown in Fig.(2).

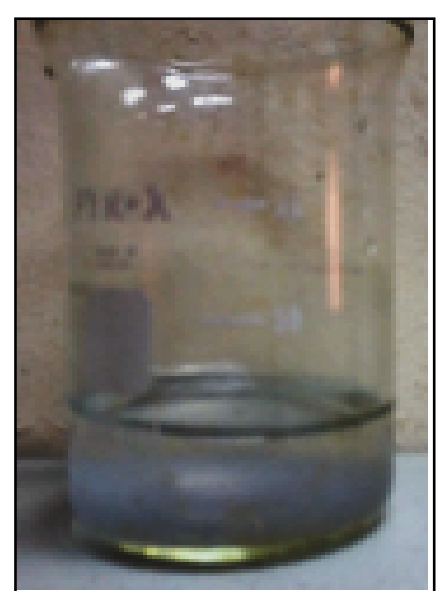

Fig.(2): Boehmite Nanoparticles.

\section{II- Characterization of Boehmite NPs}

After arc discharge technique, the optical absorption spectrum was recorded at room temperature by UV-Vis double beam spectrophotometer (Shimadzu) using optical quartz cell with $1 \mathrm{~cm}$ optical path, the pattern was recorded in the range of wavelength (200 - 900) $\mathrm{nm}$. In order to explain the structure and surface morphology of boehmite NPs, the boehmite colloidal dried on silicon and glass substrates by drop casting technique at $40{ }^{\circ} \mathrm{C}$. The structure of the boehmite film examined by (Shimuzu) X-Ray diffractometer, with source $\mathrm{CuK} \alpha$ radiation of the wavelength is $1.5405 \AA$, a pattern recorded in the range $2 \theta$ from $10^{\circ}-80^{\circ}$. The vibrotational frequencies between the atoms bonds were analyzed by (FTIR) type Shimadzu. The average diameter of particles for bohmite nps was obtained by AFM type A Solver P-47H.

\section{III- Antibacterial test}

Antibacterial activity of boehmite NPs was analyzed against Gram-negative bacteria (Escherichia coli) and Gram-positive bacteria (Staphylococcus aurous) strains by diffusion method.

The bacteria farms have been developed at the nutrient and placed in an incubator for 24 hour at $37^{\circ} \mathrm{C}$ in order to have good growth. Then the bacteria was diluted by normal saline in order to obtain $10^{5}$ to $10^{7}$ Colony-Forming Units per $\mathrm{ml}$ (CFU./ml) cell comparable with the tube of McFarland Standard number 0.5, then the positive (Staphylococcus aurous) and negative bacteria (Escherichia coli) was distributed on the surface of the separated 
Petri-dishes, which contained on the nutrient agar.

To determine the inhibitory effect, Filter papers were prepared as a disc with $5 \mathrm{~mm}$ diameter and immersed in the boehmite nanosuspension. After the saturation the discs from the boehmite NPs, put on surface of the Petri-dishes. The diameter about the discs can be represented the inhibition zones of micobes and it's reflect the magnitude of susceptibility of microbes.

\section{Results and discussion}

\section{I- Characterizations of Boehmite NPs}

X-Ray Diffraction pattern used to determine the phase structure and the crystallite size. (XRD) pattern of boehmite NPs deposited on silicon substrate is shown in Fig.(3); it observed that boehmite is polycrystalline structure.

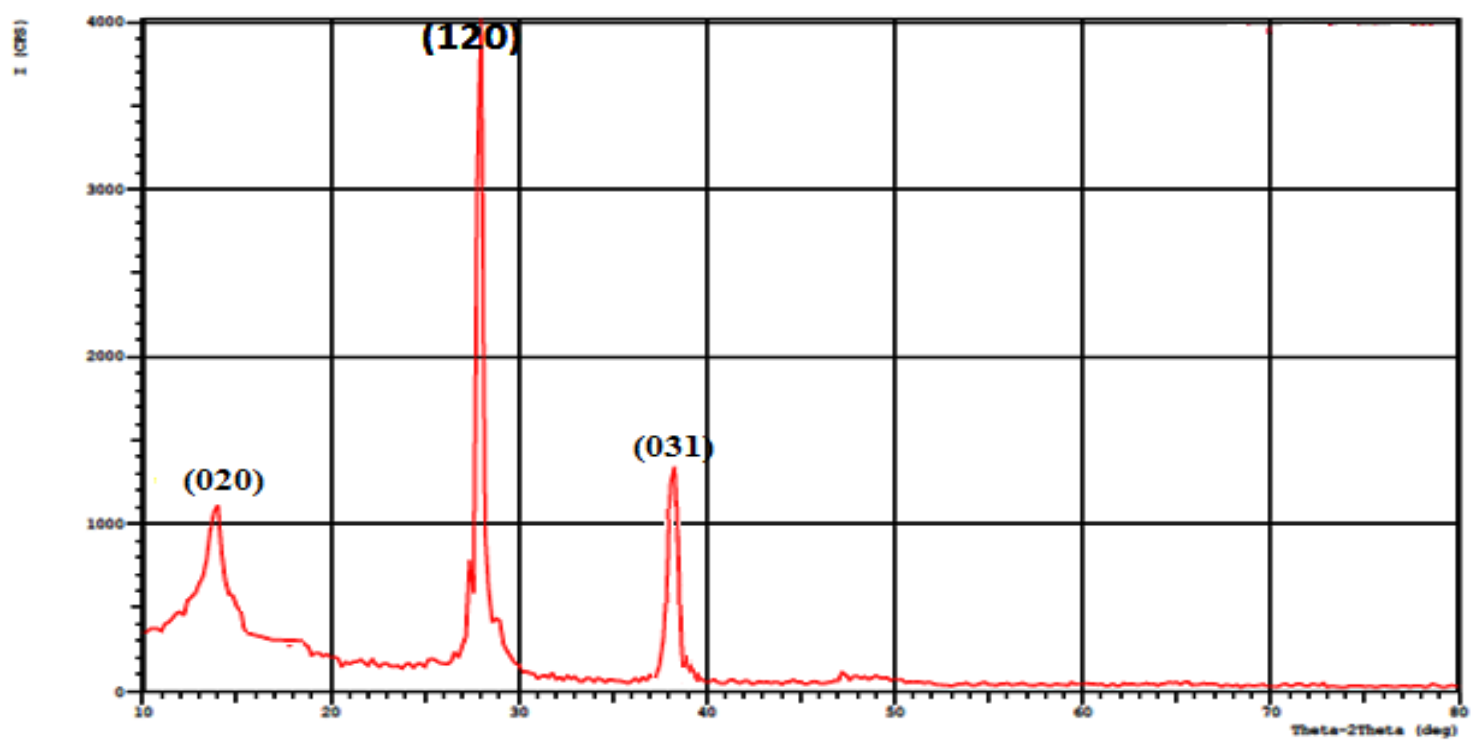

Fig.(3): XRD pattern of Boehmite nanoparticles.

The diffraction peaks at $13.7^{\circ}, 28^{\circ}$ and $38^{\circ}$ could be related to (020), (120) and (031) miller indices of lattice planes of the pure orthorhombic structure of gamma-AlOOH affirmed by standard JCPDS data (File card No. 21-1307) [8].

The average grain size of boehmite nanoparticles can be estimated by using Scherrer equation: [9]

$$
\mathrm{Dg}=\frac{\mathrm{K} \lambda}{\beta \cos \theta}
$$

Where $\mathrm{Dg}$ is the grain size, $\mathrm{K}$ is is the correction factor in the Debye Scherer equation ,its equal to $(0.94), \lambda$ is the wavelength of incident X-ray radiation (1.5404 $\AA$ for $\mathrm{CuKa}$ ), $\beta$ is pure full width of the diffraction line at half of the maximum intensity (FWHM) of peak and $\theta$ is the Bragg angle [10].

The hkl miller indices, FWHM and grain size of boehmite NPs orthorhombic structure from XRD investigated in Table (1). 
Table (1)

The hkl, FWHM and grain size of Boehmite NPs orthorhombic structure from XRD spectrum.

\begin{tabular}{|c|c|c|c|c|c|}
\hline $\begin{array}{c}\text { Diffraction } \\
\text { angles(2O) } \\
\text { degree }\end{array}$ & $\begin{array}{c}\text { Relative } \\
\text { intensity } \\
\mathbf{I} / \mathrm{I}_{1} \times 100 \\
\text { XRD }\end{array}$ & $\begin{array}{c}\text { d spacing }(\AA) \\
\text { XRD }\end{array}$ & $\begin{array}{l}\text { (h k l) } \\
\text { Miller } \\
\text { indices }\end{array}$ & $\begin{array}{r}\text { FWHM } \\
\text { (Degree) }\end{array}$ & $\begin{array}{c}\text { Grain } \\
\text { size }(\mathbf{n m})\end{array}$ \\
\hline 13.7 & 26 & 6.418 & $(020)$ & 1.2379 & 10.20 \\
\hline 28 & 100 & 3.194 & $(120)$ & 0.5519 & 20.97 \\
\hline 38 & 34 & 5.306 & $(031)$ & 0.8423 & 21.68 \\
\hline
\end{tabular}

Therefore the grain size of boehmite nanoparticles is ranging from 10.20 to 21.68 nm.

The FTIR spectrum of boehmite nanoparticles was recorded between $400 \mathrm{~cm}^{-1}$ to $4000 \mathrm{~cm}^{-1}$ wave number as shown in Fig.(4).

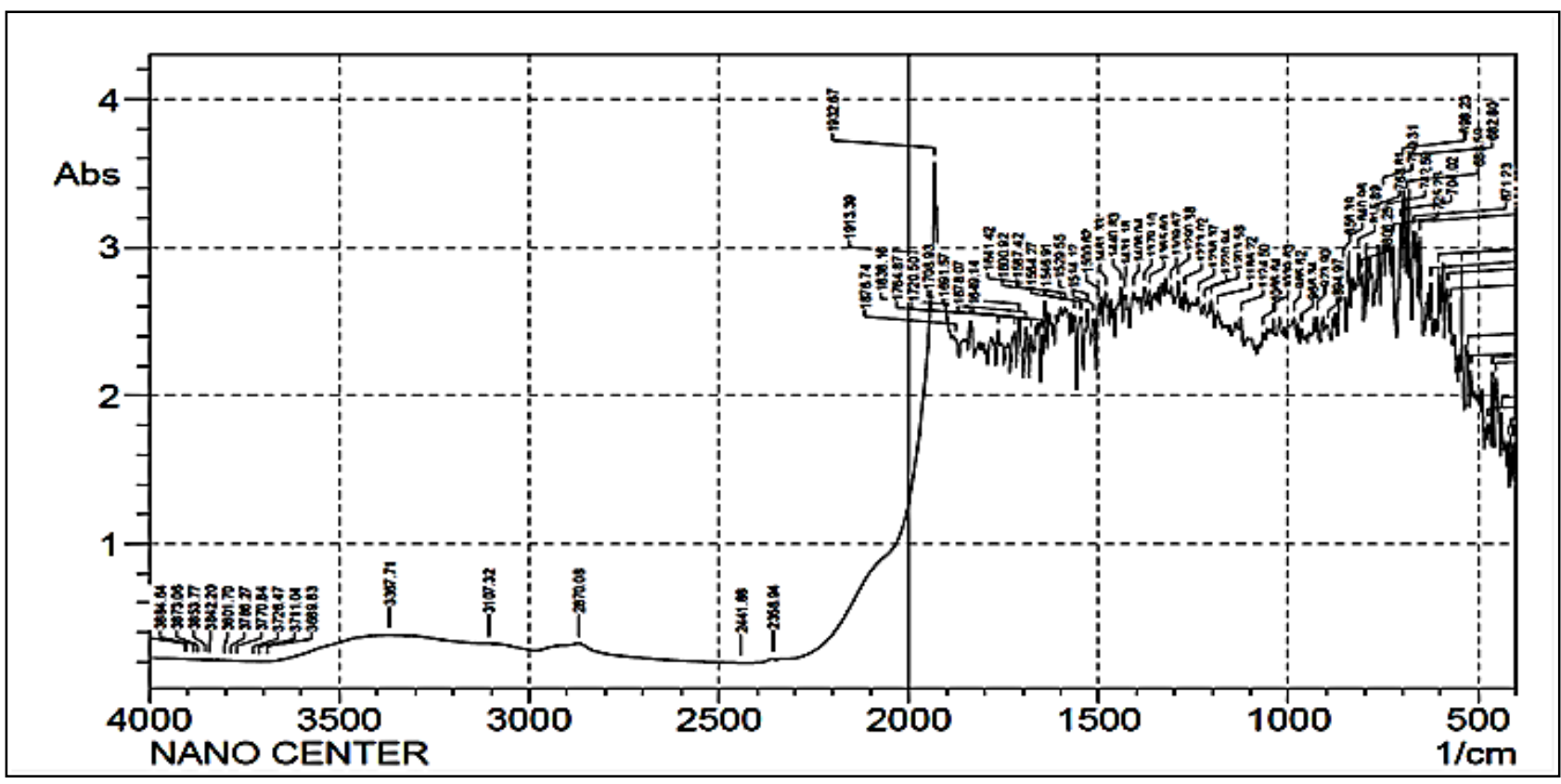

Fig.(4): FTIR spectrum of boehmite nanoparticles.

From Fig.(4) there are many absorption peaks related to the boehmite material, the octahedron region which extends from (400$800 \mathrm{~cm}^{-1}$ ) corresponding to the vibrational frequencies of $\mathrm{Al}-\mathrm{O}$ bonding, The bands observed around $620 \mathrm{~cm}^{-1}, 570$ and $480 \mathrm{~cm}^{-1}$ are associated with the stretching modes of AlO6, however the wide band appearing between $\left(800 \mathrm{~cm}^{-1}-1300 \mathrm{~cm}^{-1}\right)$ corresponds to the Al-OH bending [11]. The infrared peaks located at $(1481.33,1431.18,1379,1379.10$, 1365.60,1309.67,1203.58 and $1273.02 \mathrm{~cm}^{-1}$ ) are related to the $\mathrm{C}-\mathrm{O}$ vibration modes, in addition the absorption peaks at (1500.62,
$1529.55,1546.91,1587.42$ and $1600 \mathrm{~cm}^{-1}$ wave number are corresponding to the stretching mode of the carboxyl group $(\mathrm{C}=\mathrm{O})$ [12], these peaks refer to little contribution of $\mathrm{CO}_{2}$ dissolution from air contain. The Absorption peaks at $(3884,3689.83,3367$ and $3107.32 \mathrm{~cm}^{-1}$ ) are related to the harmonics of $\mathrm{H}-\mathrm{OH}$ stretching bonding modes of water [13].

Atomic force Microscope was used for characterization of boehmite nanoparticles, it offers information about physical properties including average diameter, shape and size distribution of nanoparticles. 
Fig.(5) (a,b) show the topography images of the boehmite NPs, The bright points in the image show the nanoparticles and the intensity of color reflects the height of the particles.

The amplitude parameters obtained from two-dimensional image includes the root mean square, average roughness and the average diameter of boehmite NPs deposited on glass substrate. The root mean square, average roughness and the average diameter were 0.998, 0.859 and $89 \mathrm{~nm}$ respectively. Three dimensional image reveals ordered arrays of spherical shape and homogeneous particles distribution.

Fig.(5)(c) shows the percentage of boehmite NPs as a function of the diameter, this figure show that the size of grains varies from 20 to $140 \mathrm{~nm}$.

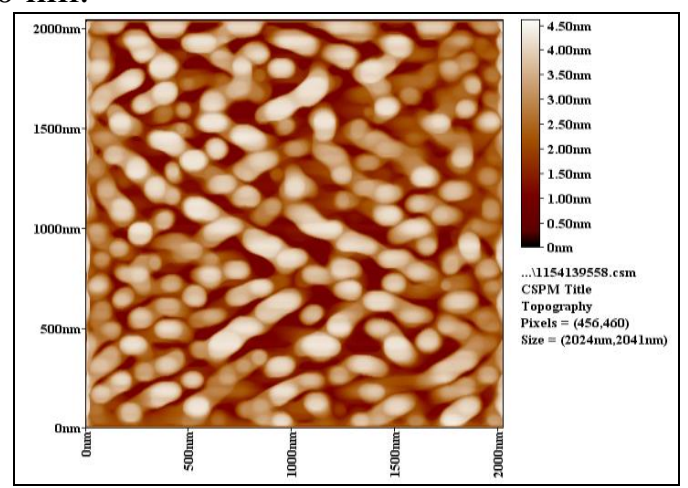

(a)

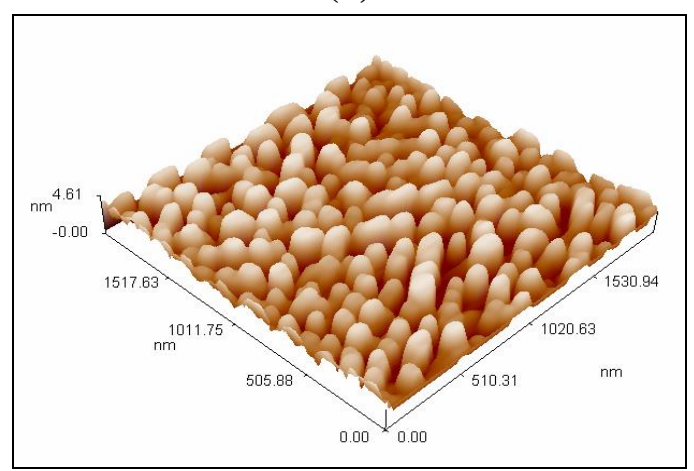

(b)

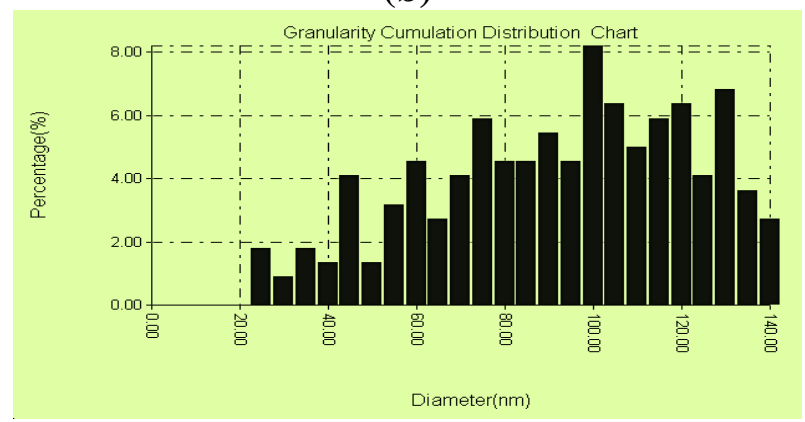

(c)

Fig.(5): (a) Two-dimensional AFM image,

(b) Three-dimensional AFM image,

(c) Granularity accumulation distribution of Boehmite nanoparticles.
Fig.(6) shows the absorption spectrum of boehmite nanoparticles.

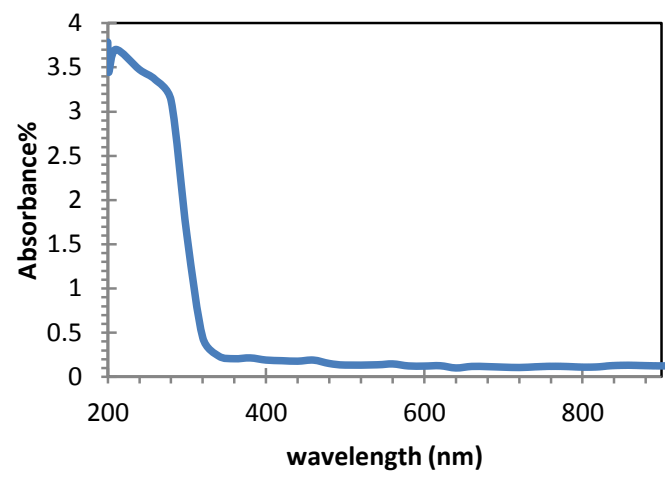

Fig.(6): Absorption peak of boehmite NPs.

This figure demonstrates the absorption peak of the boehmite nanoparticles located in the Ultra-violet region, and substantial drop in the amount of absorbance in the visible and infrared regions, which means that the Boehmite Nps have a high energy gap, This increase band gap due to the by fundamental light absorption process, Absorption by the free carriers consignment and mainly quantum confinement effect [14].

The optical band gap energy $(\mathrm{Eg})$ of the boehmite nanoparticles calculated from experimental relationship between the absorption coefficient $(\alpha)$ and band gap energy (Eg) [15].

$$
\alpha h v=A(h v-E g)^{1 / 2}
$$

Where $\alpha$ : Absorption coefficient, h: Planks constant, v: photon frequency, A: constant, Eg: band gap energy.

The direct band gap can be deduced by plotting between square of $(\alpha h v)^{2}$ versus photon energy (hv). Then intersection of the straight line tangent to the curve with the $\mathrm{x}$ axis, the point of intersection represents a direct energy gap of the boehmite NPs which the absorption coefficient is equal to zero at this point as shown in Fig.(7). 


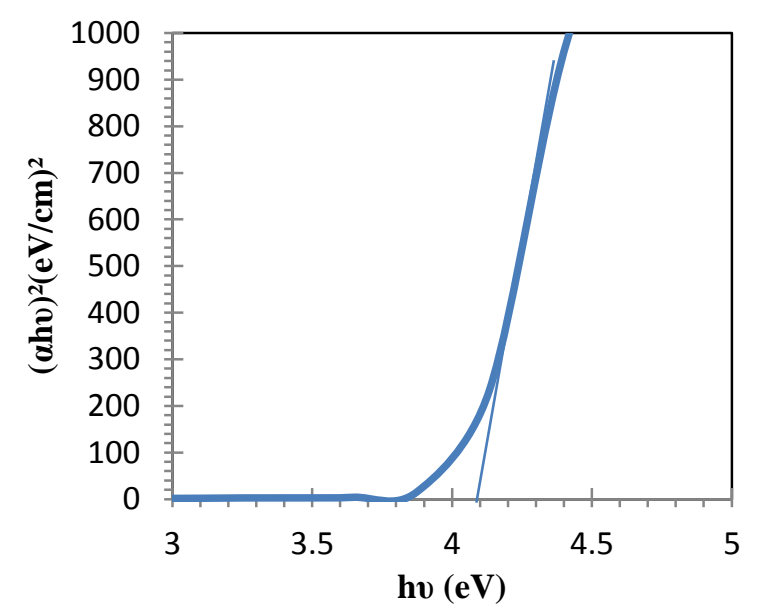

Fig.(7): Plot of $(\alpha h v)^{2}$ vs. photon energy(hv) of boehmite NPs.

As presented in Fig.(7) the value of the optical band gap of boehmite NPs is $4.1 \mathrm{eV}$, this amount is almost agreement with the band gap data which reported in the article [16].

\section{II- Antibacterial Activity of boehmite NPs}

Fig.(8) illustrates the inhibition zones of $\mathrm{AlO}(\mathrm{OH})$ nanoparticles against two types of bacteria, Gram-positive (Staphylococcus aureus) and Gram -negative (Escherichia coli).

The regions around the filter papers containing the nanoparticles reflect the exposure of bacteria to these particles as well as the effectiveness of these particles to kill these bacteria [6].

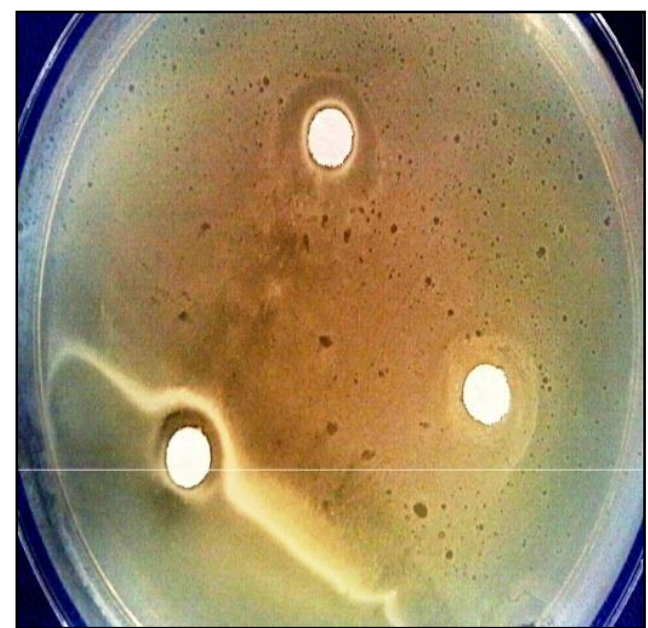

(a)

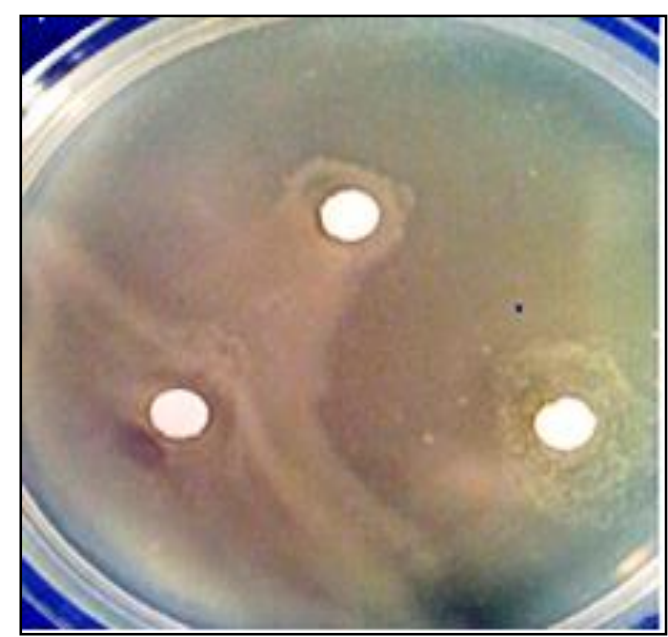

(b)

Fig. (8): ${ }^{\text {Zone }}$ of inhibition of (a) Staphylococcus aureus and (b) Escherichia coli.

Antibacterial properties of boehmite nanoparticles come from; the diameter of nanoparticles is smaller than compared with the diameter of bacteria cell which a few micrometers. Thus, the particles are able to penetrate the bacteria cell [17], quantum confinement effect and large the ratio between surface area and its volume [18] due to generate of Reactive Oxygen Species (ROS) on the surface of nanoparticles and released 
high toxicity AlO ions [19], Resulting in the occurrence of the electrostatic interaction between bacteria and $\mathrm{AlO}$ ions, along with hydrophobic interactions and polymer bridging, which reason to damage of DNA by exerting oxidative stress and thereafter cell death [17].

Table (2) shows the diameter of inhibition zone of boehmite Nps.

Table (2)

Diameter of inhibition zone of Boehmite NPs.

\begin{tabular}{|c|c|c|}
\hline Bacteria type & $\begin{array}{c}\text { Diameter of } \\
\text { inhabitation } \\
\text { zone (mm) }\end{array}$ & $\begin{array}{c}\text { Average } \\
\text { (mm) }\end{array}$ \\
\hline \multirow{3}{*}{$\begin{array}{c}\text { Staphylococcus } \\
\text { aureus }\end{array}$} & 13 & \multirow{3}{*}{13.66} \\
\hline & 15 & \\
\hline & 13 & \\
\hline \multirow{3}{*}{$\begin{array}{l}\text { Escherichia } \\
\text { coli }\end{array}$} & 12 & \multirow{3}{*}{11.66} \\
\hline & 13 & \\
\hline & 10 & \\
\hline
\end{tabular}

The diameter of inhibition zone is obtained through measured the diameter which around the filter papers, it is found that the average diameter of the inhibition zone of Staphylococcus aureus bacteria is larger compared with the average diameter the inhibition zone of Escherichia coli, This means that S-aureus bacteria had the highest sensitivity toward boehmite NPs while E- coli aurous bacterial showed the least sensitivity and higher negative resistance/tolerance against boehmite NPs.

This result is in agreement with Premanathan et al, who reported that the nanoparticle effect is more pronounced against Gram-positive bacterial strains than Gramnegative bacteria strains [20].

\section{Conclusions}

The characterization and antibacterial results demonstrate that there is able to synthesize a high-quality boehmite nanoparticles using simple, room temperature arc discharge method. The XRD result revealed the presence of diffraction peaks related to the orthoramtic structure of gamma $\mathrm{AlO}(\mathrm{OH})$. FTIR result show that the presence of the vibrational frequencies at $\left(400-800 \mathrm{~cm}^{-1}\right)$ corresponding to the Al-O bonding. AFM result indicated that the boehmite have the average diameter is $89 \mathrm{~nm}$, optical properties showed that the energy gap is $4.1 \mathrm{eV}$, its larger than compared with the boehmite in bulk structure as a result to the quantum confinement effect. The antibacterial results demonstrate that $\mathrm{AlO}(\mathrm{OH})$ nanoparticles have wide range of antibacterial effects on different bacteria, including both Gram-positive (Staphaureus) and Gram-negative (E-coli) bacteria is mainly due to the particulate $\mathrm{AlO}(\mathrm{OH})$ as the release of free $\mathrm{AlO}$ ions from $\mathrm{AlO}(\mathrm{OH})$ colloidal solution, $\mathrm{AlO}$ ions can adhere on the cell surface and cause to the damage to the cell wall. Additionally, the average diameter of the inhibition zone of Staphylococcus aureus is larger than the Escherichia coli; this means that Staphylococcus aureus bacteria exhibited the highest sensitivity toward boehmite NPs while Escherichia coli aurous bacteria showed the least sensitivity.

\section{References}

[1] Ali K., Mahdi M., Mohammad B., Atena S., "Boehmite nanoparticle catalyst for the one-pot multicomponent synthesis of 3,4dihydropyrimidin-2-(1H)-ones and thiones under solvent-free conditions", Chinese Journal of Catalysis, 35(3), 362-367, 2014.

[2] Priyank M., Ryuzo S., Jun F., "Boehmite nanorod/gold nanoparticle nanocomposite film for an easy-to-use optical humidity sensor", Japan advanced institute of science and technology.

[3] FU G., WANG J., XU Bing, GAO Hong, "Influence of hydrothermal temperature on structure and microstructure of boehmite", Science Direct, 20, s221-s225, 2010.

[4] Zhi Chen, Dudu Wu, Jiaxi Chen, "Investigation of pseudo boehmite nanoparticles as antibacterial agent", Applied Physics A, 119 (4), 1515-1522, 2015.

[5] Goran S., "Microstructural Analysis of Boehmite Nanoparticles Prepared by Rapid Hydrolysis of Aluminum Sec-butoxide", Original Scientific Article, 84(4), 481-485, 2011.

[6] Parkansky N., Alterkop B., R.L. Boxman, "Pulsed discharge production of nano- and microparticles in ethanol and their 
Characterization", Powder Technology.150, 36-41, (2005).

[7] Ali A., Mahmoud G., "Photocatalytic activity of metal oxide nanoparticles prepared by electrical arc Discharge method in water", Advanced Research in Physics and Engineering, 172-177.

[8] Gary G. C., Charles E. C., Douglas A. H., "The crystal structure of boehmite", clays and clay minerals, Vol. 27, No. 2, 1979, Pages 81-86.

[9] P. Scherrer, Göttinger Nachrichten Gesell, 2, 98, 1918.

[10] Sara S., Shirzad Z., Ch. Shilpa C., k.venkateswara R., "preparation and characterization of magnetite nanoparticles by sol-gel method for water treatment", International journal of innovative research in science, engineering and technology, 2(7), 2013.

[11] H. R. X. Pimentel, R. A. S. San Gil, "Contribution to the Characterization of alumina-based HDT catalysts precursors by Solid State 27Al and 17O NMR", Ann. Magn. Reson., 9(1), 12-20, 2010.

[12] Said, A. L. Sajti, S. Giorgio and W. Marine "Synthesis of nanohybrid materials by femtosecond laser ablation in liquid medium" IOP Publishing Journal of Physics: Conference Series, 59, 259-265, 2007.

[13] J. Ma, C. H. Liang, L. B. Kong, C. Wang, "Colloidal characterization and electrophoretic deposition of hydroxyapatite on titanium substrate" Journal of Materials Science: Materials in Medicine, Vol. 14(9), 797-801, 2003.

[14] E. Manea, E. Budianu, M. Purica, C. Podaru, " $\mathrm{SnO}_{2}$ thin films prepared by sol gel method for honeycomb textured silicon solar cells", journal of information Science and technology, 10 (1), 25-33, 2007.

[15] T. Arai, "The Study of the Optical Properties of Conducting Tin Oxide Films and their Interpretation in Terms of a Tentative Band Scheme", Journal physics Society, 15, 916-927, 1960.

[16] Abdolali A., Zahra H., Mahboubeh D. and Akbar Bakhtiari, "Boehmite $(\gamma$-AlOOH $)$ nanoparticles: Hydrothermal synthesis, characterization, $\mathrm{pH}$-controlled morphologies, optical properties, and DFT

calculations", physica status solidi (b), 249(6), 1264-1270, 2012.

[17] Sachindri R. and Kalaichelvan, "Antibacterial activity of metal nanoparticles, Advanced Biotech". 11 (2), 21-23, (2011).

[18] Singh S; Nalwa HS, "Nanotechnology and health safety-toxicity and risk assessments of nanostructured materials on human health". Journal Nanosciene Nanotechnology, 7, 3048-3070, 2007.

[19] Bassam G. Rasheed, Zainab I. Abd-Alwahab, "Antibacterial Silver Nanoparticles produced by Nd:YAG Laser" Al-Nahrain University, College of Engineering Journal (NUCEJ), 18(2), 315 321, 2015.

[20]- Premanathan M, Karthikeyan K, Jeyasubramanian K, Manivannan G, "Selective toxicity of $\mathrm{ZnO}$ nanoparticles toward Gram-positive bacteria and cancer cells by apoptosis through lipid peroxidation", Nanomedicine, 7, 184-192, 2011.

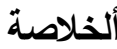

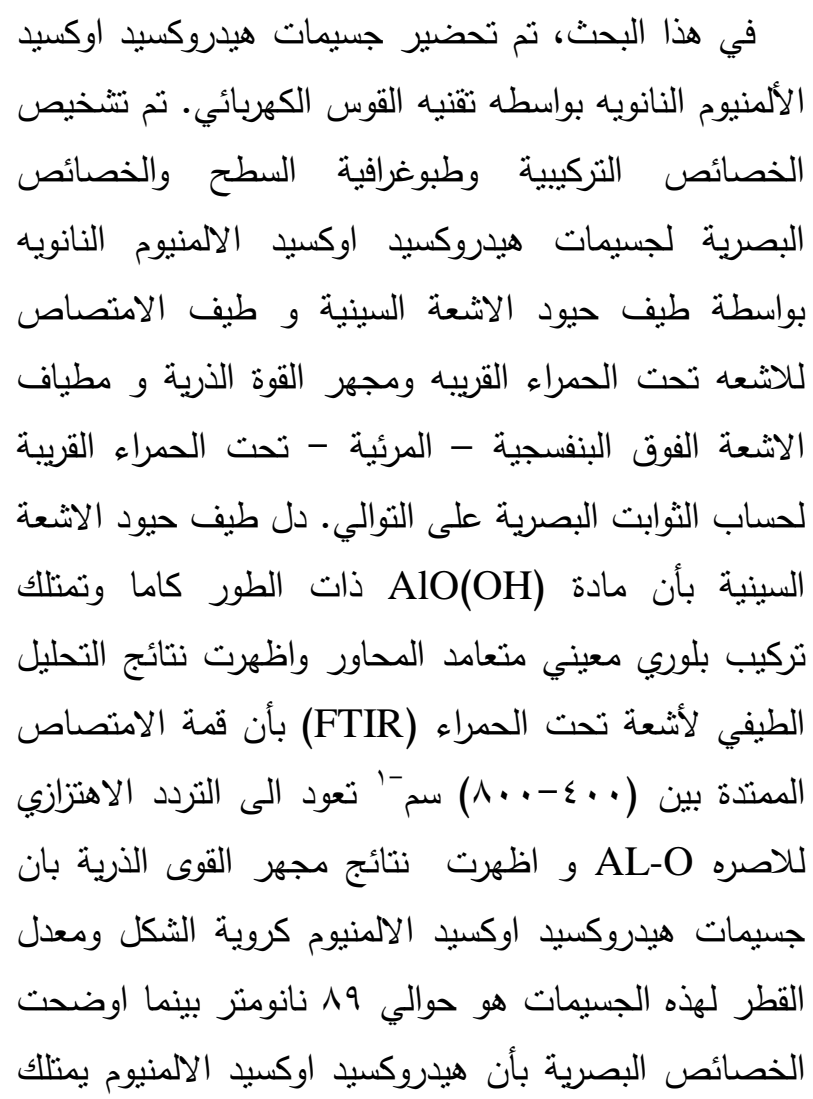




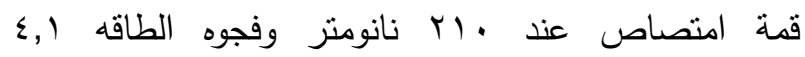
الالكترون فولت.

تم فحص قابلية جسيمات هيدروكسيد اوكسيد الالمنيوم

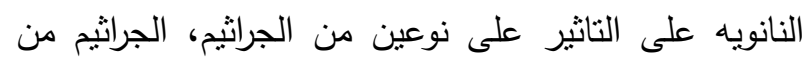

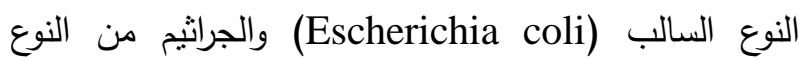
الموجب (Staphylococcus aurous). اظهرت الجرابث من النوع الموجب بأنها ذات تحسس أعلى لجسيمات الطيات

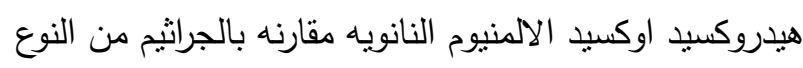

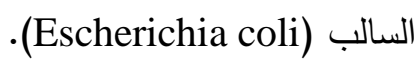

